\title{
Experimental and theoretical investigations on temperature distribution at the joint interface for copper joints using ultrasonic welding
}

\author{
Sooriya Elangovan* \\ Associate Professor, Department of Production Engineering, PSG College of Technology, Coimbatore 641004, India
}

Received 12 August 2014 / Accepted 4 October 2014

\begin{abstract}
Ultrasonic welding is a solid-state joining process that produces joints by the application of high frequency vibratory energy in the work pieces held together under pressure without melting. Copper and its alloys are extensively used in electrical and electronic industry because of its excellent electrical and thermal properties. This paper mainly focused on temperature distribution and the influence of process parameters at the joint interface while joining copper sheets using ultrasonic welding process. Experiments are carried out using $\mathrm{Cu}$ sheets $(0.2 \mathrm{~mm}$ and $0.3 \mathrm{~mm}$ thickness) and the interface temperature is measured using Data Acquisition (DAQ) System (thermocouple) and thermal imager. Numerical and finite element based model for temperature distribution at the interface are developed and solved the same using Finite Difference Method (FDM) and Finite Element Analysis (FEA). The results obtained from FDM and FEA model shows similar trend with experimental results and are found to be in good agreement.
\end{abstract}

Key words: Ultrasonic welding, Temperature distribution, Finite difference method, Finite element analysis, Mathematical modeling

\section{Introduction}

Ultrasonic Metal Welding (USMW) is a process in which two metallic parts are joined by the application of ultrasonic vibrations which are applied parallel to the interface between the parts under moderate pressure. The high frequency relative motion between the parts forms a solid-state weld. It causes progressive shearing and plastic deformation between surface asperities that disperses oxides and contaminants. It also brings in an increasing area of contact and formation of a solid and long-lasting adhesive and/or cohesive bond between the contact surfaces of metallic parts. USMW is a process of interest to several segments of manufacturing industry and lot of research activities are reported in the area of USMW and several researchers have reported their findings on the mechanism of joint formation, temperature distribution at the interface and bonding strength, etc. Some of their findings and important observations are presented below.

Daniels [1] performed preliminary studies on temperature at the interfaces by measuring the thermo electric Electromotive Force (EMF) between the work pieces during welding.

*e-mail: elango_surya@yahoo.co.in
It was observed that the temperature developed at the interface is not more than $40 \%$ of the melting point of the parent metal. De Vries [2] measured the interface temperature for welding of aluminum by infrared camera for different welding conditions. It was found that interface temperature varied from 40 to $80 \%$ of the melting point depending on the value of the parameters used for welding. Joshi [3] studied the formation of metal to metal bonds in ultrasonic welding of face centered cubic metals $(\mathrm{Al}, \mathrm{Cu}, \mathrm{Au})$ and the formation of bonds at near optimum conditions. In this study, temperature measurement was performed using infrared radio meter, liquid crystals and thermocouples. Hazlett and Ambekar [4] performed preliminary studies on the interface temperature and bonding mechanisms in USMW. Temperature rise during welding was determined using Seebeck (thermocouple) effect and measuring voltage produced between the dissimilar metals being joined and thereby measuring the average temperature over the weld area.

Suresh et al. [5] discussed temperature distribution during ultrasonic welding for an amorphous and semi-crystalline thermoplastic for several possible joint designs. In this study, it was found that the measured temperatures at interface are less than simulated results because the viscoelastic dissipation diminishes as the material heats above its glass transition 


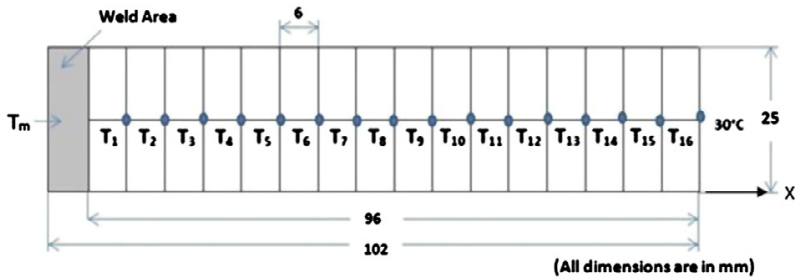

Figure 1. Specimen as per ASTM standard with boundary condition.

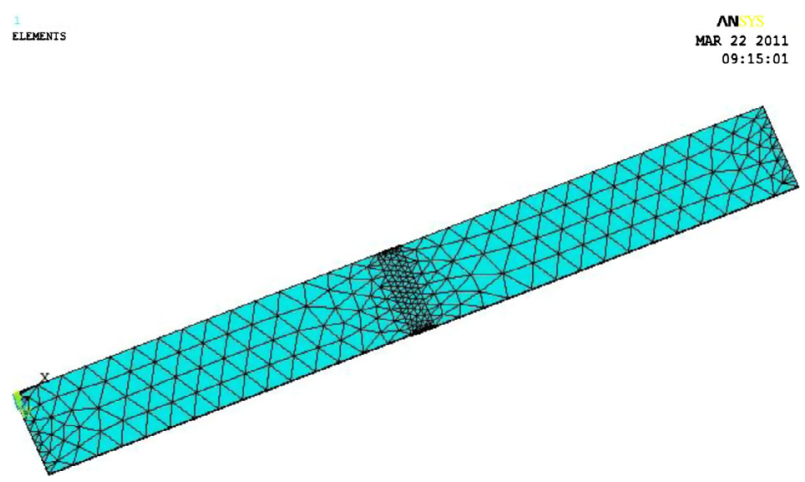

Figure 2. Meshed model for finite element analysis.

Table 1. Material properties of copper.

\begin{tabular}{lcccc}
\hline Material & $\begin{array}{c}\text { Young's } \\
\text { modulus } \\
(E)(\mathrm{GPa})\end{array}$ & $\begin{array}{c}\text { Specific } \\
\text { heat }(c) \\
(\mathrm{J} / \mathrm{kg} \mathrm{K})\end{array}$ & $\begin{array}{c}\text { Thermal } \\
\text { conductivity } \\
(k)(\mathrm{W} / \mathrm{mK})\end{array}$ & $\begin{array}{c}\text { Density } \\
(\rho)\left(\mathrm{kg} / \mathrm{m}^{3}\right)\end{array}$ \\
\hline Copper & 115 & 385 & 391 & 8940 \\
\hline
\end{tabular}

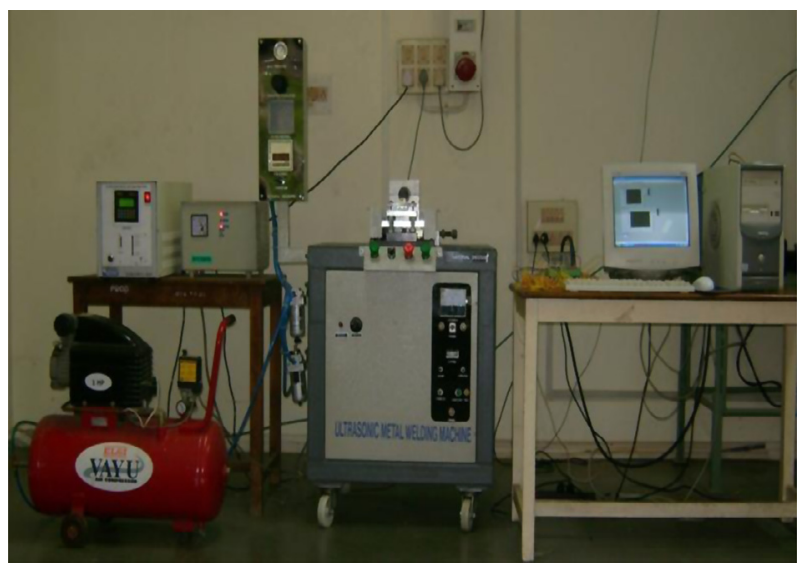

Figure 3. Experimental set up for ultrasonic metal welding.

temperature. Attarha and Sattari-Far [6] implemented three dimensional finite element simulations in gas tungsten arc welding to predict the temperature distribution in thin welded plates. The results provide good evidence for prediction of the Heat Affected Zone (HAZ). Chen and Kovacevic [7] discussed thermal and thermo-mechanical analysis of FSW of aluminum alloy 6061-T6 using a three-dimensional finite element model. It is observed that the maximum temperature gradients in longitudinal and lateral directions are located just beyond the shoulder edge. Hwang et al. [8] discussed the temperature distributions in a work piece during FSW process involving the butt joining of aluminum 6061-T6. Author used regression analysis by the least squares method to predict the temperatures at the joint line. From this study, second-order polynomial was found to be the best fit for the experimental temperatures. Soundararajan et al. [9] developed a finite element thermo-mechanical model to predict the transient temperature fields, active stresses developed and forces at the interface of the work piece and backing plate in FSW. Comparison of the temperature profile developed using adaptive and uniform contact conductance with experimental results showed the possibility of accurate determination using the present model. Elangovan et al. [10] conducted finite element based study in ultrasonic spot welding to predict the interface temperature and stress distribution during welding and their influences in the work piece, sonotrode and anvil. This study also focused to find out the effect of clamping forces, material thickness and coefficient of friction during heat generation at the weld interface. Sunar et al. [11] discussed the temperature and stress analysis of sheet metal during arc welding. In this study, a control volume approach is introduced for the numerical solution of heat transfer equations while finite element method is adopted for stress field predictions. The author found that the temperature distribution in the transverse direction does not vary considerably, but varies significantly in the longitudinal direction. Zhu and Chao [12] conducted a three-dimensional non-linear thermal and thermo-mechanical numerical simulations for the FSW of 304L stainless steel. From the observations, $50 \%$ of total mechanical energy from FSW machine is transformed into increasing the temperature of the work piece during welding.

From this literature review, it is concluded that there is enough scope to carry out research in the area of ultrasonic welding of metallic components. Measuring the temperature generated in the weld area is important for determining the quality of joint and weld strength and prediction of temperature field at the interface using FEA is found to be useful for industrial applications. This is also not found as a research finding. Also, from an academic perspective solving the unsteady state heat transfer equation with the help of Finite Difference Method (FDM) will provide scope for applied research. In this work, mathematical modeling and evaluation of temperature distribution in ultrasonic welding of metals is carried out using FDM. To help industry further the temperature field is simulated using FEA.

\section{Mathematical modeling and Finite Element Analysis}

\subsection{Mathematical modeling}

In this work mathematical model is developed to predict the temperature distribution of Copper specimens during ultrasonic welding. The real ultrasonic welding setup is represented 

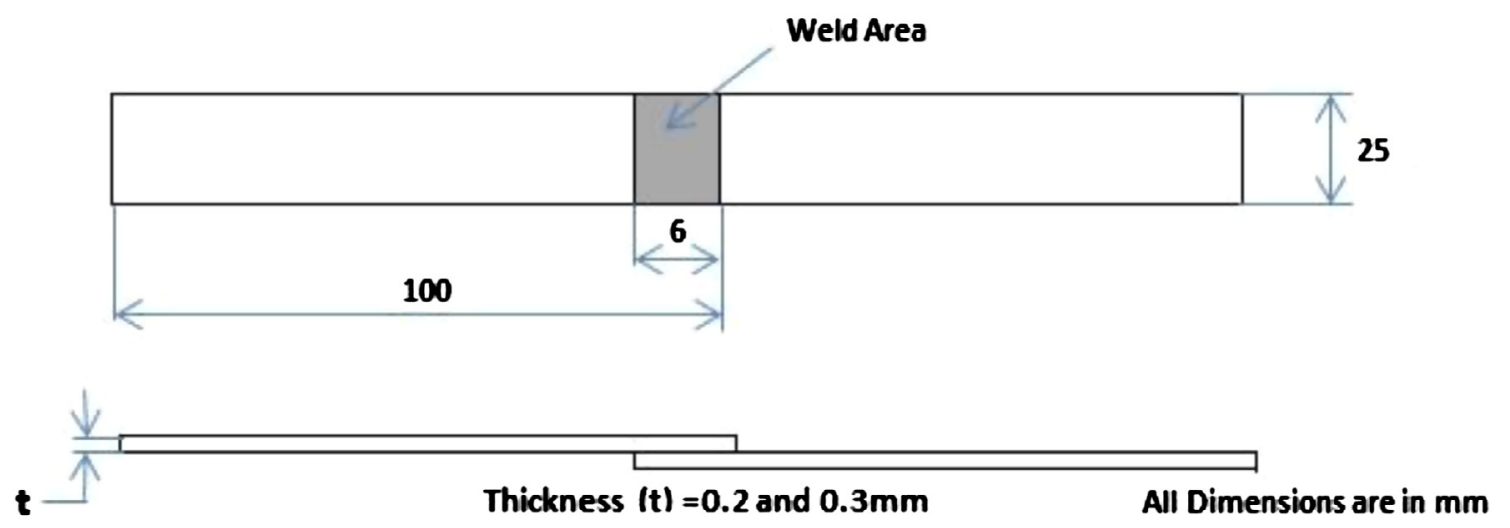

Figure 4. ASTM standards (D1002 - 01) for weld specimen.

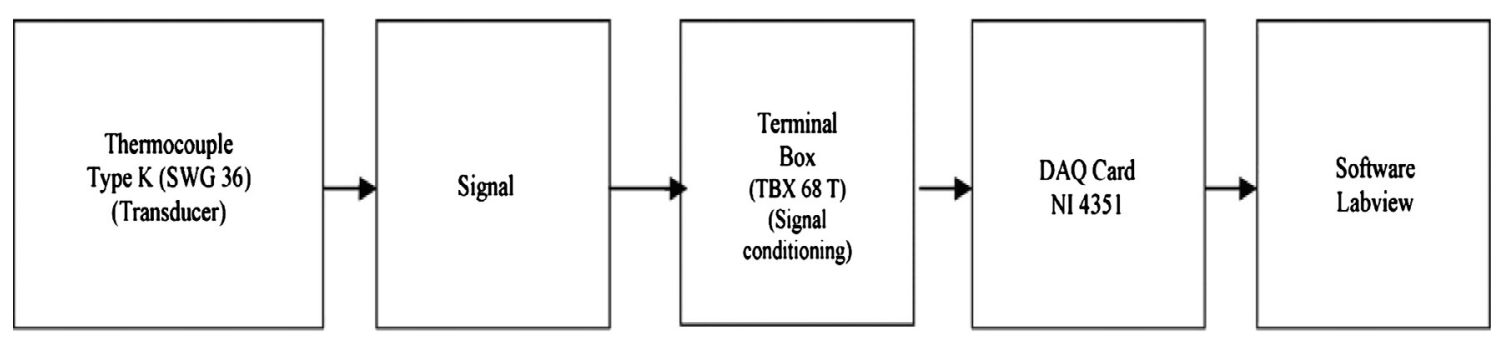

Figure 5. Block diagram for data transfer in a DAQ system.

by $1 \mathrm{D}$ unsteady state heat conduction model. Temperature distribution at each point along the longitudinal direction is obtained by solving the equation using Finite Difference Method (Crank-Nicolson method) and MATLAB software.

The unsteady state 1-D heat conduction problem can be represented by parabolic equation $[12,13]$ is shown in equation (1):

$$
c \rho \frac{\partial T}{\partial t}=k \frac{\partial^{2} T}{\partial x^{2}}
$$

where, $T=$ Temperature $(\mathrm{K}) ; k=$ Thermal conductivity $(\mathrm{W} / \mathrm{m} \mathrm{K}) ; c=$ Specific heat capacity $(\mathrm{J} / \mathrm{kg} \mathrm{K}) ; \rho=$ density $\left(\mathrm{kg} / \mathrm{m}^{3}\right)$.

In this work, one half of the specimen is considered for analysis because of symmetry as shown in Figure 1. The maximum temperature $\left(T_{\mathrm{m}}\right)$ measured by thermocouple at weld interface during welding is given as boundary condition. The entire specimen is divided into grids of size $(\Delta x) 6 \mathrm{~mm}$ along the longitudinal direction.

Initial condition:

$$
T(x, 0)=T_{0}=\text { Room temperature }=30{ }^{\circ} \mathrm{C}
$$

Boundary condition for joining $\mathrm{Cu}$ :

$$
\begin{gathered}
T_{\mathrm{m}}(x, 0)=200{ }^{\circ} \mathrm{C} \quad 0 \leq x \leq 6 \mathrm{~mm}, \\
T(x, 0)=30{ }^{\circ} \mathrm{C} \quad 6 \mathrm{~mm} \leq x \leq 102 \mathrm{~mm} .
\end{gathered}
$$

Procedure for solving the simultaneous equations using Crank-Nicolson method for $\mathrm{Cu}$ specimens is explained in Appendix.

\subsection{Finite Element Analysis (FEA)}

Finite Element Analysis is a computational technique used to obtain approximate solution of problems in engineering by discretization of a complex physical domain into very small pieces (of user-designated size) called elements [14]. For problems involving complicated geometries, loadings, and material properties, it is generally not possible to obtain closed form solutions. Analytical solutions are those given by a mathematical expression that yields the values of the desired unknown quantities at any location in a body and are thus valid for an infinite number of locations in the body. These analytical solutions generally require the solution of ordinary or partial differential equations, which, because of the complicated geometries, loadings, and material properties, are not usually obtainable. Hence the need to rely on numerical methods such as finite element method for acceptable solutions.

The finite element formulation of the problem results in a system of simultaneous algebraic equations for solution, rather than requiring the solution of differential equations. These numerical methods yield approximate values of the unknowns at discrete numbers of points in the continuum. Thus, this process of modeling a body by dividing it into an equivalent system of smaller bodies or units (finite elements) interconnected at points common to two or more elements (nodal points or nodes) and/or boundary lines and/or surfaces is called discretization. In the finite element method, instead of solving the problem for the entire body in one operation, the equations are formulated for each finite element and combined them to obtain the solution of the whole body [15]. 

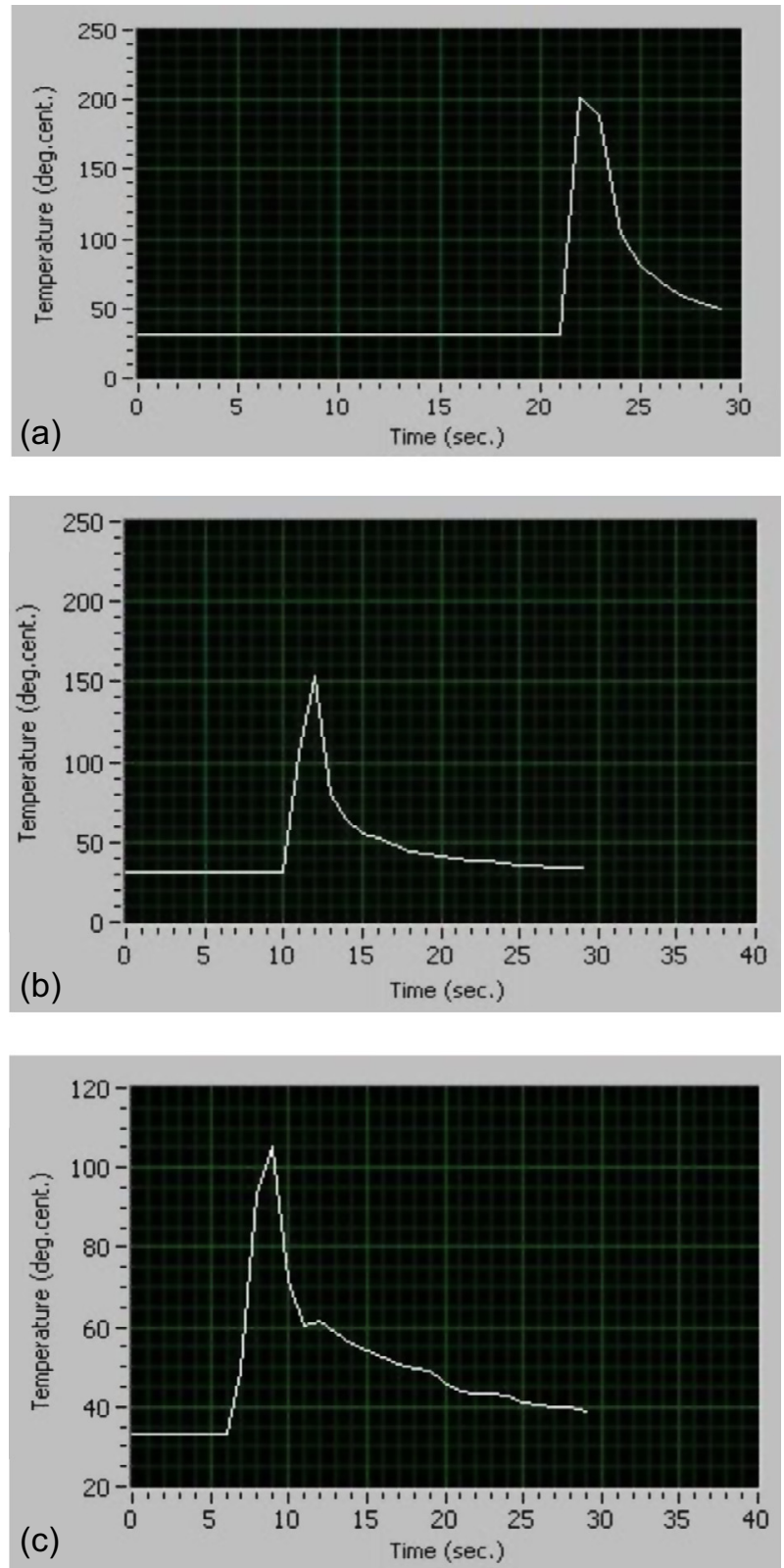

Figure 6. Maximum interface temperature (a) $0.3 \mathrm{~mm}$, seam weld - $57 \mu \mathrm{m}$, (b) $0.3 \mathrm{~mm}$, seam weld $-42.5 \mu \mathrm{m}$, (c) $0.3 \mathrm{~mm}$, seam weld $-28 \mu \mathrm{m}$.

\subsection{Simulation of temperature distribution}

In ultrasonic welding, temperature is generated at the joint interface during welding process. Generation of heat and the subsequent change of temperature have a significant impact on the properties of welded joint. In this study, modeling and simulation of temperature distribution during ultrasonic welding of $\mathrm{Cu}$ specimens of different thicknesses was done using ANSYS software.

Components are modeled and element type is chosen based on the type of analysis using ANSYS element reference guide.
The model is meshed and simulation is carried out on the meshed component. Figure 2 shows the meshed model of ultrasonically welded specimens.

The material properties considered for thermal analysis are coefficient of thermal conductivity $(k)$, specific heat $(c)$, Young's modulus and density. The properties copper work pieces [16] are listed in Table 1. A 3D ten-noded solid 87 element is selected for this thermal analysis. It has one degree of freedom (temperature at each node). The element is applicable to a $3 \mathrm{D}$, steady state or transient thermal analysis. Two-D 3-Node surface-to-surface contact (CONTA172) is used to represent contact surfaces and 2-D target element (TARGE169) is used to represent the target surfaces for the associated contact elements.

In this analysis heat flux generated as a result of the deformation $\left(Q_{\mathrm{w}}\right)$ occurring at weld interface is given as input. Heat generation due to deformation [2] is the power dissipated over the weld area. Heat flux due to deformation $\left(Q_{\mathrm{w}}\right)$ is a function of yield strength, clamping force and amplitude. The calculated heat flux is given on the nodes of the contact area of the work piece to obtain the temperature distribution. Simulations are carried out for various conditions and the results obtained from thermal analysis are presented in Section 4.

\section{Experimental work}

The experimental setup for the USMW is shown in Figure 3 with Data Acquisition (DAQ) system. Welding was carried out using a conventional ultrasonic metal welding machine $(2500 \mathrm{~W}, 20 \mathrm{kHz})$ for different ranges of weld parameters. Experiments are carried out using design matrix as developed in previous work [17]. In this work horn made of hardened steel with diamond knurl pattern (seam and spot) and anvil made of steel with serrations on top surface are used. The horn is serrated near the tip for preventing the work piece from sliding during welding. To measure the interface temperature during welding, one end of the thermocouple (K-type) is connected to the weld interface and the other end is connected to the terminal block of the DAQ system. This DAQ system is interfaced with Labview software.

$\mathrm{Cu}$ sheets $(0.2 \mathrm{~mm}$ and $0.3 \mathrm{~mm}$ thickness $)$ have been selected for the experimental work. Before welding, samples are cleaned with acetone to remove the surface impurities as it may affect the bond strength. The specimens of copper are prepared as per the ASTM international codes [18] for Standard Test Methods for Tensile Testing of Metallic Materials (Figure 4). In order to find out the weld strength, a computerized tensile testing machine is used.

\subsection{Measurement of interface temperature}

Temperature generated at the weld interface during welding is measured using thermocouple with Data Acquisition (DAQ) System and thermal imager for various combinations of parameters and materials. Figure 5 shows the block diagram representing data transfer in a DAQ system. In K-type 

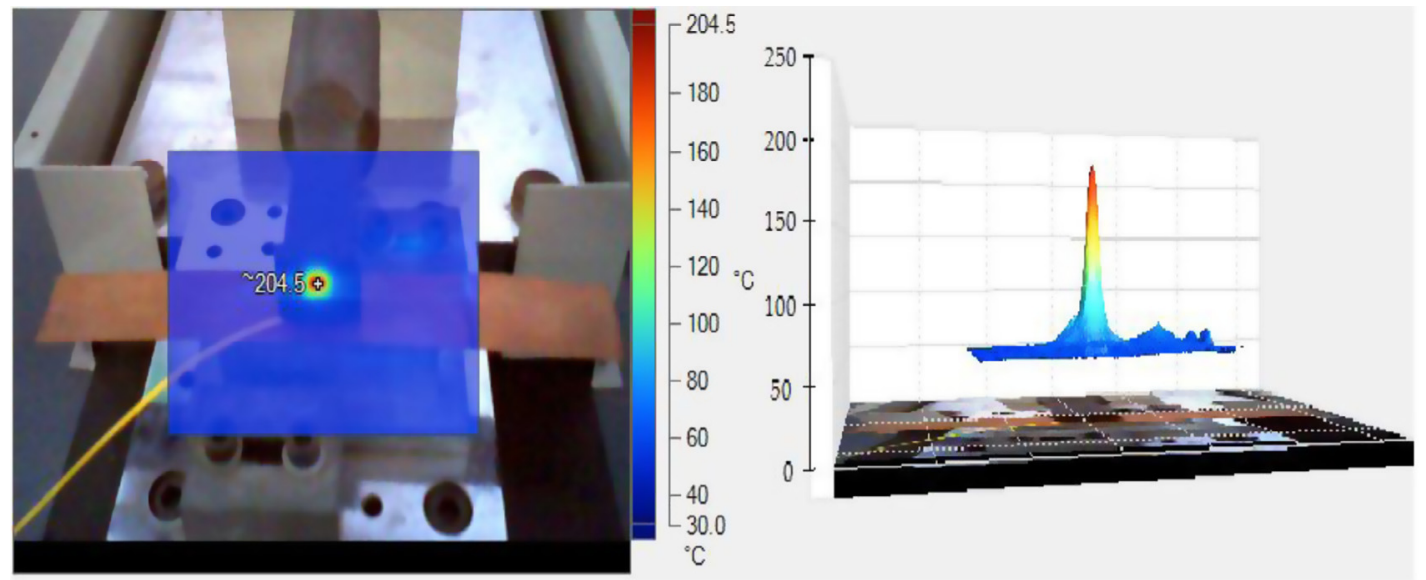

(a)
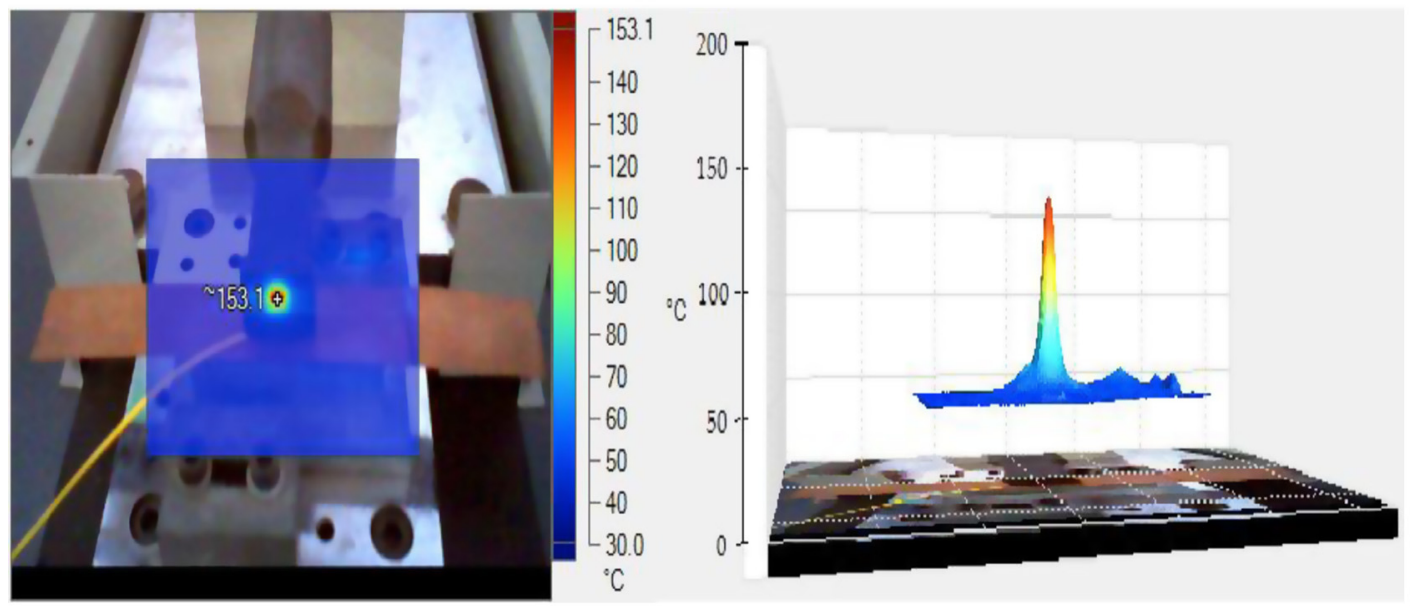

(b)

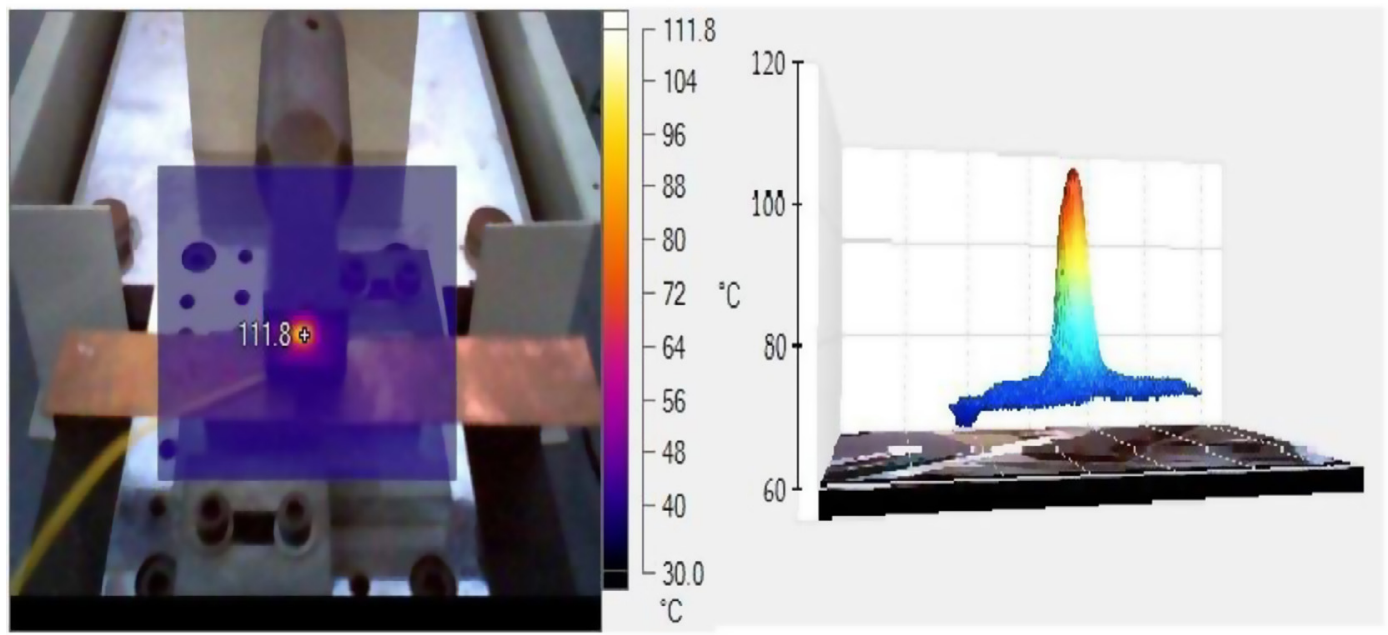

(c)

Figure 7. Maximum interface temperature (Thermal imager) (a) $0.3 \mathrm{~mm}$, seam weld $-57 \mu \mathrm{m}$, (b) $0.3 \mathrm{~mm}$, seam weld $-42.5 \mu \mathrm{m}$, (c) $0.3 \mathrm{~mm}$, seam weld $-28 \mu \mathrm{m}$. 
Table 2. Temperature distribution during welding ( $\mathrm{Cu}$, seam weld, $0.3 \mathrm{~mm})$.

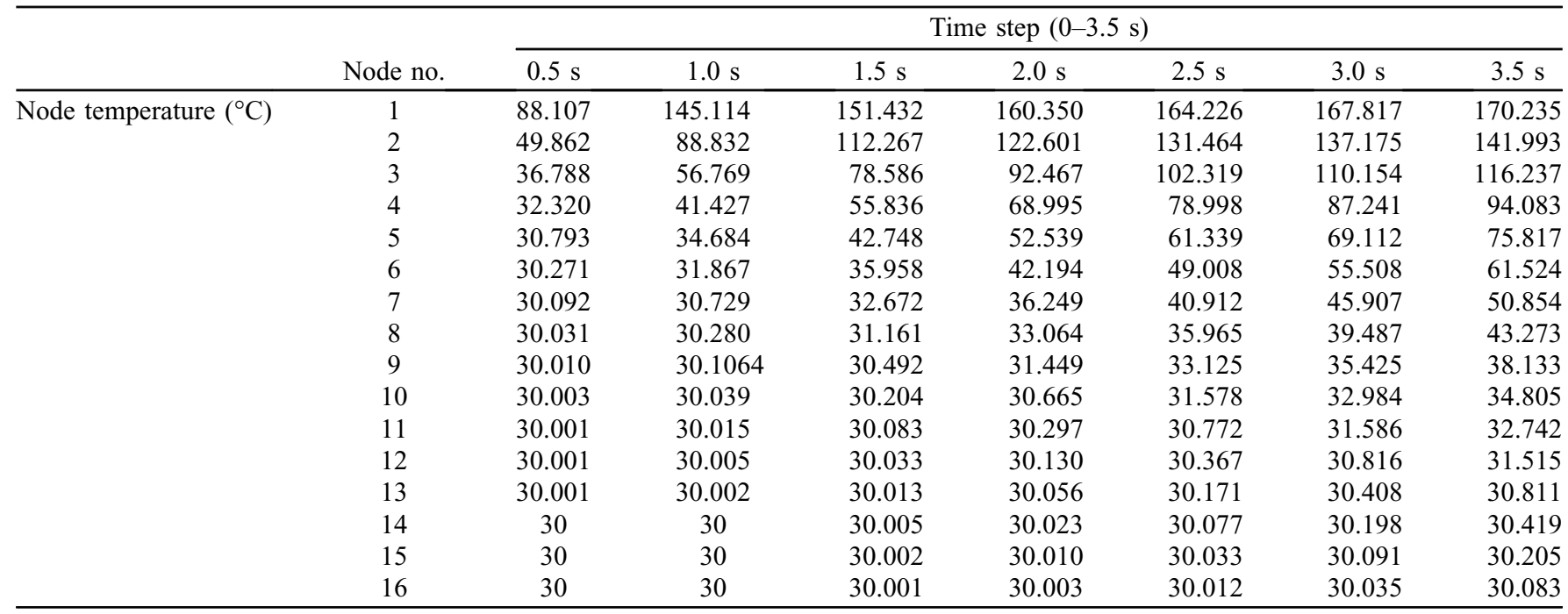

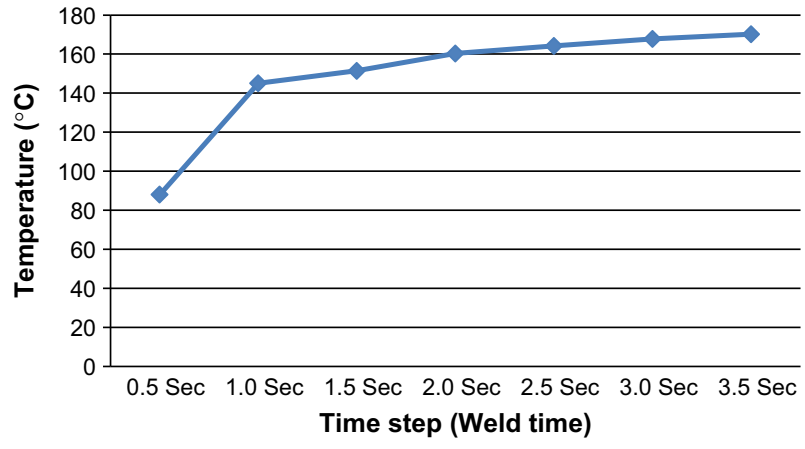

Figure 8. Variation of temperatures for node no. 1 with time $(\mathrm{Cu})$.

thermocouple one of the constituent metals is Nickel, which has magnetic behavior that undergoes a step change at its curie temperature. The Curie temperature for Nickel is $354{ }^{\circ} \mathrm{C}$. This thermocouple can measure temperatures from $-180{ }^{\circ} \mathrm{C}$ to $+1300{ }^{\circ} \mathrm{C}$. It has a high accuracy of $1.5^{\circ} \mathrm{C}$ on each side from $-40{ }^{\circ} \mathrm{C}$ to $+375^{\circ} \mathrm{C}$. The electrical signal generated by the thermocouple is converted into temperature values and displayed in graphical form by Labview. The DAQ system used in this study has a data acquisition rate of 1000 inputs/second which enables the generation of a smooth and precise temperature distribution.

A thermal imaging camera consists of five components: an optic system, detector, amplifier, signal processing, and display unit. These parts work together to render infrared radiation, such as that given off by warm objects or flames, into a visible light representation. The camera display shows infrared output differentials, so that two objects with the same temperature will appear to be of the same color. Temperatures measured at the weld interface during welding using thermocouple and thermal imager for $\mathrm{Cu}$ material and the inferences from these measurements are discussed in Section 4.

\section{Results and discussion}

\subsection{Results and discussion from temperature measurement}

During USMW, temperature developed at the interface was measured for different levels of parameters using thermocouple with Labview software and thermal imager for joints using $\mathrm{Cu}$ sheets. In Labview software, maximum temperature obtained at the weld interface is shown as a graph and in thermal imager the output is in the form of an infrared image. Meanwhile, temperature developed at the weld interface is simulated using FEA software (ANSYS-10) which is explained later.

Figure 6 shows the maximum interface temperature obtained with thermocouples using Labview software for seam welding of $0.3 \mathrm{~mm}$ thick $\mathrm{Cu}$ specimens at different levels of amplitude. The maximum temperatures at the interface obtained for high, medium and low level of amplitude are $200{ }^{\circ} \mathrm{C}, 155^{\circ} \mathrm{C}$ and $110^{\circ} \mathrm{C}$ respectively. Time taken to reach maximum temperature at weld interface is $2-3 \mathrm{~s}$. Similarly, Figure 7 shows the maximum interface temperature measured using thermal imager for same level of amplitude. The maximum interface temperatures obtained from thermal imager at high, medium and low level of amplitude are $204.5^{\circ} \mathrm{C}$, $153.1^{\circ} \mathrm{C}$ and $111.8^{\circ} \mathrm{C}$ respectively. The difference at higher temperatures is due to the changes in emissivity of the surface and this influences the temperature measurement when thermal imager is used.

\subsection{Results and discussion from mathematical modeling}

Temperature developed at the weld interface was modeled using unsteady state heat transfer equation and solved using Finite Difference Method (FDM) and MATLAB software. 


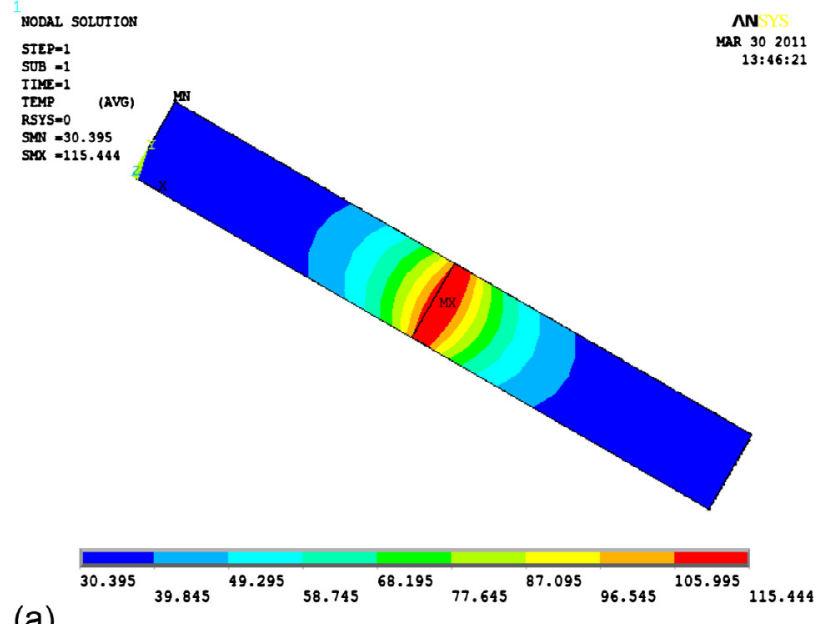

(a)

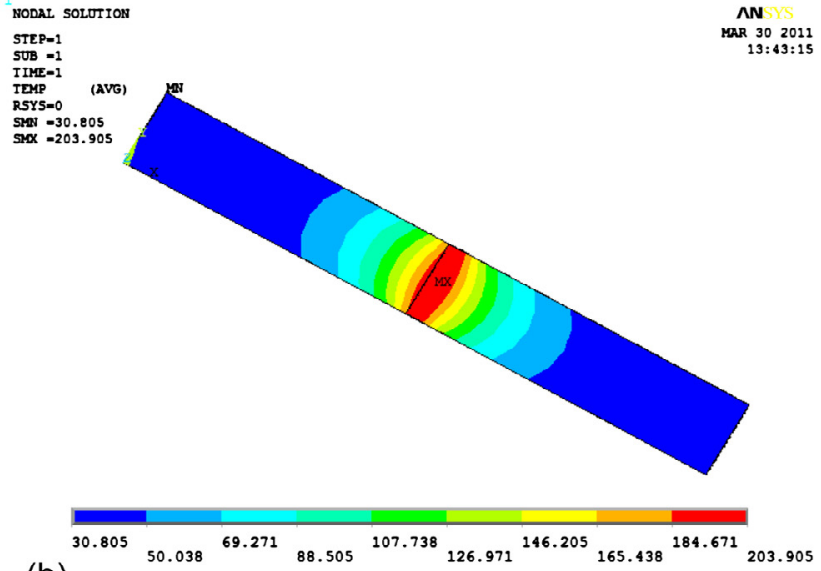

(b)

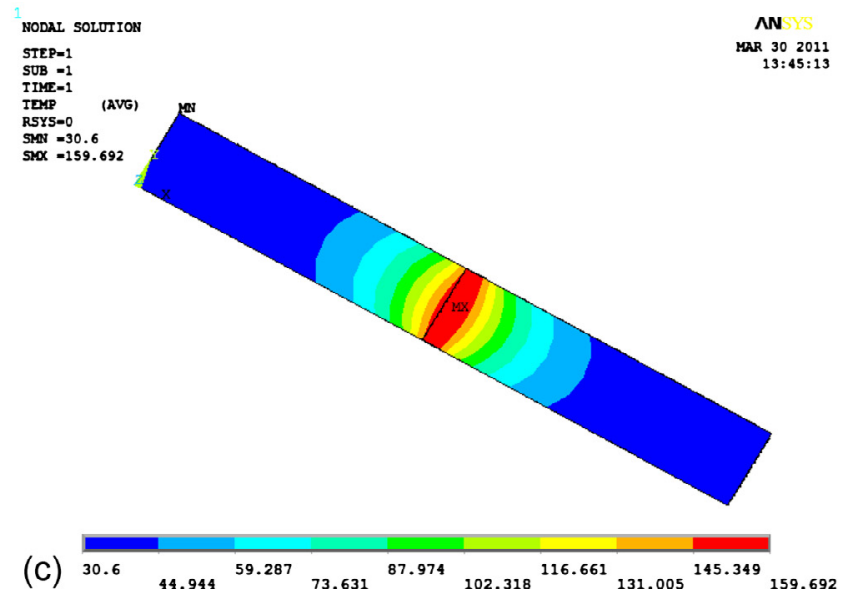

Figure 9. Temperature distribution for joining $\mathrm{Cu}$ (a) $0.3 \mathrm{~mm}$, seam weld - Amplitude $57 \mu \mathrm{m}$, (b) $0.3 \mathrm{~mm}$, seam weld - Amplitude $42.5 \mu \mathrm{m}$, (c) $0.3 \mathrm{~mm}$, seam weld - Amplitude $28 \mu \mathrm{m}$.

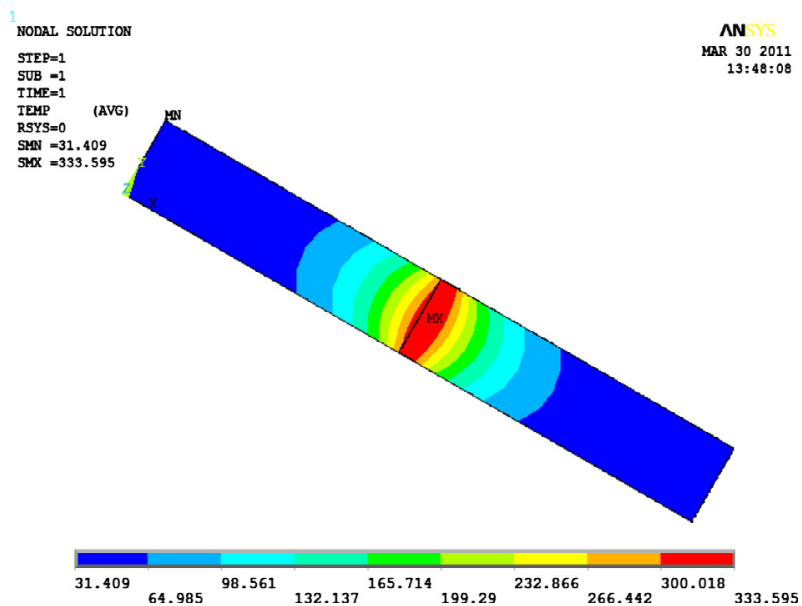

Figure 10. Temperature distribution for joining $\mathrm{Cu}(0.2 \mathrm{~mm}$, seam weld - Amplitude $57 \mu \mathrm{m})$.

Results obtained from FDM based studies for the welding of $\mathrm{Cu}$ specimens are discussed here. Table 2 shows the temperature distribution value obtained from mathematical modeling and solving using Crank-Nicolson method with an input temperature $\left(T_{\mathrm{m}}\right)$ of $200{ }^{\circ} \mathrm{C}$ for $\mathrm{Cu}$. The time step for calculating the temperature distribution is $0.5 \mathrm{~s}$ and is calculated for $3.5 \mathrm{~s}$. From the table, it is inferred that maximum temperature of $170.235{ }^{\circ} \mathrm{C}$ is attained at end of the weld time $(3.5 \mathrm{~s})$ for node point no: 01 . Figure 8 shows the temperature rise with time for the specimen at node point no: 01 . The distribution of temperatures obtained is showing similar trend with experimental observations. The model is for the seam welding of $\mathrm{Cu}$ specimens with a thickness of $0.3 \mathrm{~mm}$.

From Figure 8 and Table 2, it is inferred that temperature increases with increase in weld time. This is because increase in weld time gives sufficient time to disrupt the contaminants and causes a good metal to metal contact and high level of rubbing action. This causes increase in interface temperature.

\subsection{Results and discussion from FEA}

Temperature developed at the weld interface was simulated using FEA software (ANSYS-10.0). Results obtained from FEA based studies and the effects of interaction between the variables for joining $\mathrm{Cu}$ are discussed here. 


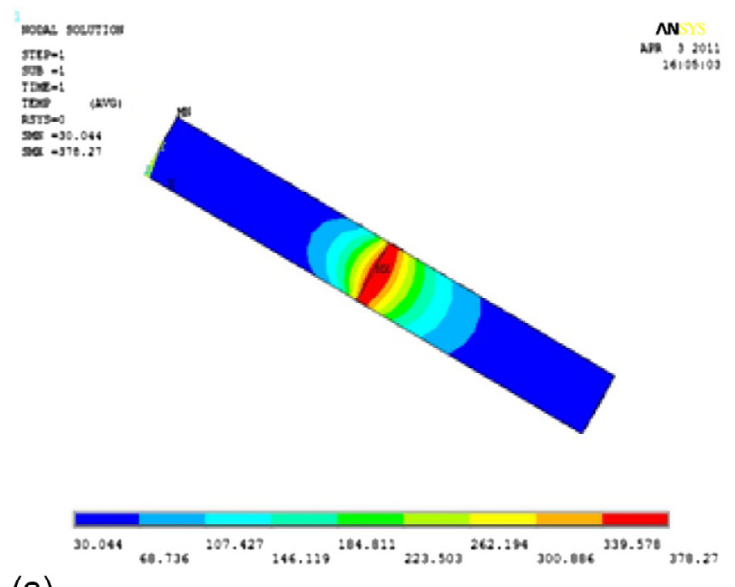

(a)

Figure 11. Temperature distributions for joining $\mathrm{Cu}$ (spot weld), weld - Amplitude $57 \mu \mathrm{m}$.

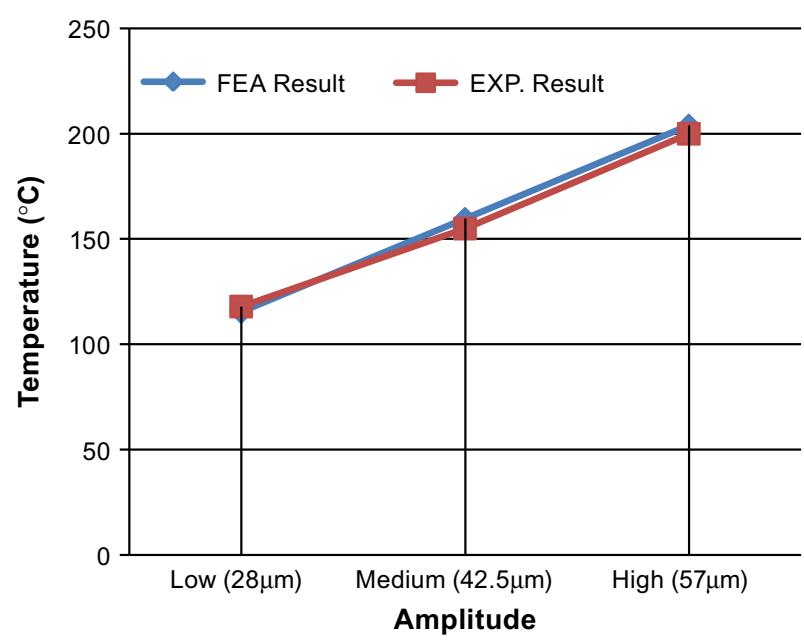

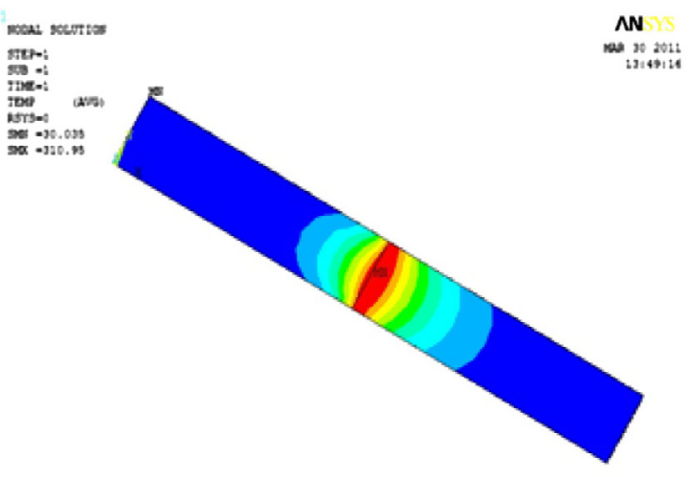

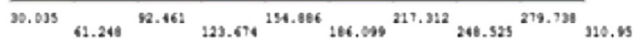

(b)

(a) $0.2 \mathrm{~mm}$, spot weld - Amplitude $57 \mu \mathrm{m}$, (b) $0.3 \mathrm{~mm}$, spot

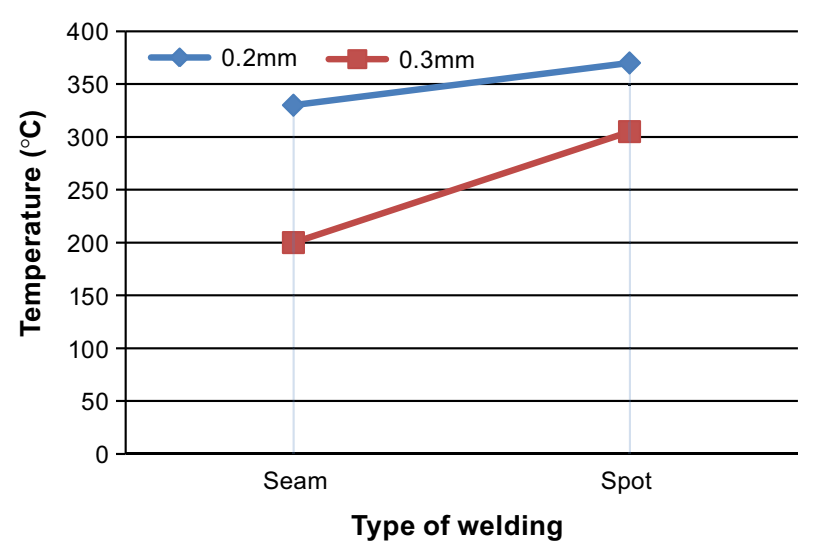

Figure 13. Comparison of interface temperature for seam and spot welding.

Figure 12. Effect of amplitude on interface temperature.

Table 3. Comparison of interface temperatures $(\mathrm{Cu})$.

\begin{tabular}{lcccc}
\hline & USMW & & \multicolumn{2}{c}{ Maximum interface temperature $\left({ }^{\circ} \mathrm{C}\right)$} \\
\cline { 3 - 5 } Type of welding & Thickness $(\mathrm{mm})$ & & Experiments & Thermal imager \\
\cline { 3 - 5 } & & & Thermocouple (Labview) & NA \\
\hline Seam & 0.2 & 330 & 204.5 & NA \\
Spot & 0.3 & 333.56 & 203.9 \\
& 0.2 & 305 & NA & 378.27 \\
& 0.3 & & 310.95 \\
\hline
\end{tabular}

Figure 9 shows the simulated results obtained from FEA for welding of $\mathrm{Cu}$ specimens at different level of amplitude. The maximum interface temperatures obtained from FEA at high, medium and low level of amplitude are $203.9^{\circ} \mathrm{C}$, $159.692{ }^{\circ} \mathrm{C}$ and $115.4{ }^{\circ} \mathrm{C}$ respectively. Figures 10 and 11 show the simulated results of interface temperature obtained from FEA for seam and spot welding of copper specimens.

From Figures 6, 7 and 9, it is inferred that maximum temperature generated at the interface during welding increases with increase of amplitude which is shown in the Figure 12. This is in agreement with the observations from experiments
(Figures $6 a-6 c$ and Figures $7 a-7 c$ ). This is because increase in amplitude gives increased sliding action between the contact surfaces. This leads plastic deformation and rise in interface temperature.

Similarly from Figure 13, it is inferred that interface temperature increases with decrease in thickness for same levels of parameters. As thickness increases, mass increases and the rate of sliding motion decreases. With a thin section sliding motion is at a higher level. Hence higher temperature for thin joints. Also, it is inferred that maximum interface temperature obtained in spot welding is higher than that of seam welding 
for same thickness (Figure 13). Here, the mass to be moved is less owing to reduced area. Spot weld is stronger than seam weld because more energy is concentrated on a small area and that gives improved penetration. In seam weld more area is available and the same energy is dissipated over this area leading to reduced penetration.

Comparison of interface temperature obtained from experimental measurements and FEA for seam and spot welding of specimens of $\mathrm{Cu}$ are shown in Table 3. While comparing the simulated results obtained from FEA with experimental results, it is observed that the deviations are minimum and is found that they are in good agreement. Hence the adequacy of the developed models. Thermal imager used for this study can measure a maximum temperature of $250{ }^{\circ} \mathrm{C}$. So, the temperature value beyond $250{ }^{\circ} \mathrm{C}$ was not mentioned in Table 3. FDM based model gives error as the assumptions made are not close to reality and grid size is large.

\section{Conclusions}

From mathematical modeling and solving using FDM, it is inferred that temperature increases with increase in weld time. This is because increase in weld time gives sufficient time to disrupt the contaminants which causes a good metal to metal contact and high level of rubbing action. This causes high levels of friction that increases interface temperature. The results agree reasonably well with experimental values. Temperature distribution during welding of $\mathrm{Cu}$ was predicted by FEA. The results obtained from FEA model shows similar trend with experimental results and are found to be in good agreement. Temperature distribution obtained from FEA and experimental results shows that interface temperature increases with decrease in thickness for same levels of parameters. This is because, as thickness is increased, mass is increased and the rate of sliding motion decreases. With a thin section sliding motion is at a higher level. Hence higher temperature for thin joints.

Also, it is inferred that maximum interface temperature obtained in spot welding is higher than that of seam welding for same thickness. Spot weld is stronger than seam weld because more energy is concentrated on a small area and that gives improved penetration. In seam weld more area is available and the same energy is dissipated over this area leading to reduced penetration. Maximum temperature at weld interface increases with increase of amplitude of horn. This is because increase in amplitude gives increased sliding action between the contact surfaces. This leads to plastic deformation and rise in interface temperature. Also the intensity of wave is varying with square of amplitude.

Acknowledgements. The authors express their sincere thanks to the Management and Principal of PSG College of Technology, Coimbatore for providing necessary support and infrastructure to carry out this work. We are grateful to AICTE, New Delhi for funding this research work under research promotion scheme. (F.No: 8023/BOR/RID/RPS - 136/2007-08).

\section{References}

1. H.P.C. Daniels, Ultrasonic welding, Ultrasonics 3, OctoberDecember (1965) 190-196.

2. E. De Vries, Mechanics and mechanism of ultrasonic metal welding, PhD thesis, The Ohio State University, 2004.

3. K.C. Joshi, The formation of ultrasonic bond between metals, Welding Journal 50 (1971) 840-848.

4. T.H. Hazlett, S.M. Ambekar, Additional studies on interface temperatures and bonding mechanisms of ultrasonic welds, Welding Journal 49 (1970) 196-s-200-s.

5. K.S. Suresh, M. Rooparani, K. Prakasan, R. Rudramoorthy, Modelling of temperature distribution in ultrasonic welding of thermoplastics for various joint designs, Journal of Materials Processing Technology 186 (2007) 138-146.

6. M.J. Attarha, I. Sattari-Far, Study on welding temperature distribution in thin welded plates through experimental measurements and finite element simulation, Journal of Materials Processing Technology 211 (2011) 688-694.

7. C.M. Chen, R. Kovacevic, Finite element modeling of friction stir welding-thermal and thermo-mechanical analysis, Journal of Machine Tools and Manufacture 43 (2003) 1319-1326.

8. Y.M. Hwang, Z.W. Kang, Y.C. Chiou, H.H. Hsu, Experimental study on temperature distributions within the work piece during friction stir welding of aluminum alloys, Journal of Machine Tools and Manufacture 48 (2008) 778-787.

9. V. Soundararajan, S. Zekovic, R. Kovacevic, Thermo-mechanical model with adaptive boundary conditions for friction stir welding of Al 6061, Journal of Machine Tools and Manufacture 45 (2005) 1577-1587.

10. S. Elangovan, S. Semeer, K. Prakasan, Temperature and stress distribution in ultrasonic metal welding - an FEA-based study, Journal of Materials Processing Technology 209 (2009) 1143-1150.

11. M. Sunar, B.S. Yilbas, K. Boran, Thermal and stress analysis of a sheet metal in welding, Journal of Materials Processing Technology 172 (2006) 123-129.

12. X.K. Zhu, Y.J. Chao, Numerical simulation of transient temperature and residual stresses in friction stir welding of 304L stainless steel, Journal of Materials Processing Technology 146 (2004) 263-272.

13. Steven C. Chopra, Raymond P. Canale, Numerical methods for engineers. 6th ed., Tata McGraw Hill, New York, 2010.

14. D.V. Hutton, Fundamentals of finite element analysis. 2nd ed., McGraw-Hill, New York, 2004.

15. D.L. Logan, A first course in the finite element method. 3rd ed., Thomson Publication, Pacific Grove, Ca, 2002.

16. ASM, ASM hand book, Properties and selection: non-ferrous alloys and special purpose materials, Vol. 2, 13th ed., ASM international, 1998.

17. S. Elangovan, Experimental and theoretical investigations on ultrasonic metal welding and optimisation of process parameters to achieve quality welds, $\mathrm{PhD}$ thesis, Anna University Chennai, 2011.

18. D.M. Stefanesce (Editor), ASM hand book, standard test method for apparent shear strength of single-lap-joint adhesively bonded metal specimens by tension loading (metal-tometal), Vol. 15, ASM international, 2005. 


\section{Appendix}

\section{Solutions of unsteady state heat transfer equations using Crank Nicolson Method}

The Crank Nicolson method is an implicit central difference (Finite Difference) method used to solve the heat flow problems and partial differential equations numerically. Central difference method produces truncation error in terms of $\Delta x^{2}$ which is very less compared to forward and backward difference method which produces error in terms of $\Delta x$. Although implicit methods are very complicated, this method is used as it is convergent and stable for large time step

In Crank Nicolson method central difference approximation to time derivative $\left(\frac{\partial T}{\partial x}\right)$ and central difference approximation for second order distance derivative $\left(\frac{\partial^{2} T}{\partial x^{2}}\right)$ can be determined by averaging the difference approximations at the beginning and end of the time increment step [13]. So the Equation (1) is rewritten as follows.

$$
\begin{gathered}
\frac{1}{2} x\left(\left(\frac{\partial^{2} T}{\partial x^{2}}\right)^{j}+\left(\frac{\partial^{2} T}{\partial x^{2}}\right)^{j+1}\right)=\frac{c \rho}{k} x \frac{\partial T}{\partial x} \\
\frac{1}{2} \times\left(\begin{array}{c}
\left(\frac{T_{i+1}^{j}-2 T_{i}^{j}+T_{i-1}^{j}}{\Delta x^{2}}\right) \\
+\left(\frac{T_{i+1}^{j+1}-2 T_{i}^{j+1}+T_{i-1}^{j+1}}{\Delta x^{2}}\right)
\end{array}\right)=\frac{c \rho}{k} \times\left(\frac{T_{i}^{j}-T_{i}^{j}}{\Delta t}\right) .
\end{gathered}
$$

When Equation (A2) is rearranged, Crank Nicolson formula is obtained as follows.

$$
-r T_{i+1}^{j+1}+(2+2 r) T_{i}^{j+1}-r T_{i-1}^{j+1}=-r T_{i-1}^{j}+(2-2 r) T_{i}^{j}+r T_{i+1}^{j}
$$

where

$$
r=\frac{k \Delta t}{c \rho(\Delta x)^{2}}
$$

For copper, the thermal conductivity, heat capacity and density are taken from ASM Hand Book [16].

$$
\begin{gathered}
k=391 \mathrm{~W} / \mathrm{m}^{\circ} \mathrm{C} \\
c=385 \mathrm{~J} / \mathrm{Kg}{ }^{\circ} \mathrm{C} \\
\rho=8940 \mathrm{~kg} / \mathrm{m}^{3}
\end{gathered}
$$

where, $\Delta t=0.5 \mathrm{~s}$ and $\Delta x=0.006 \mathrm{~m}$

Substituting the value of $r$ in Equation (A3)

$$
\begin{gathered}
r=\frac{391 \times 0.5}{385 \times 8940 \times(0.006)^{2}} \\
r=1.578 .
\end{gathered}
$$

$$
\left[\begin{array}{c}
-1.578 T_{i+1}^{j+1}+5.156 T_{i}^{j+1} \\
-1.578 T_{i-1}^{j+1}
\end{array}\right]=\left[\begin{array}{c}
1.578 T_{i+1}^{j}-1.156 T_{i}^{j} \\
+1.578 T_{i-1}^{j}
\end{array}\right]
$$

Let, $i=$ distance derivative

$j=$ time derivative

The Equation (A3) is applied to grid points of the specimen for first time step,

$$
\left[\begin{array}{c}
-1.578 T_{2}^{1}+5.156 T_{1}^{1} \\
-1.578 T_{0}^{1}
\end{array}\right]=\left[\begin{array}{c}
1.578 T_{2}-1.156 T_{1} \\
+1.578 T_{0}
\end{array}\right] .
$$

General equation for the first and last interior nodes [13].

First interior node:

$$
2(1+r) T_{1}^{j+1}-r T_{2}^{j+1}=r f_{0}\left(t^{j}\right)+2(1-r) T_{1}^{j}+r T_{2}^{j}+r f_{0}\left(t^{j+1}\right) .
$$


Last interior node:

$$
-r T_{i-1}^{j+1}+2(1+r) T_{i}^{j+1}=\left[\begin{array}{c}
r f_{i+1}\left(t^{j}\right)+2(1-r) T_{i}^{j} \\
+r T_{i-1}^{j}+r f_{i+1}\left(t^{j+1}\right)
\end{array}\right]
$$

where

$$
\begin{gathered}
f_{0}\left(t^{j}\right)=T_{0}^{j}=200{ }^{\circ} \mathrm{C} \\
f_{0}\left(t^{j+1}\right)=T_{0}^{j+1}=200{ }^{\circ} \mathrm{C} \\
f_{i+1}\left(t^{j}\right)=30{ }^{\circ} \mathrm{C} \\
f_{i+1}\left(t^{j+1}\right)=30{ }^{\circ} \mathrm{C} .
\end{gathered}
$$

By solving the Equations (A5), (A7), (A8) following simultaneous equations are obtained for $0.5 \mathrm{~s}$ time step

$$
\begin{gathered}
i=1, j=0 \\
5.156 T_{1}^{1}-1.578 T_{2}^{1}=375.6 \\
i=2, j=0 \\
-1.578 T_{1}^{1}+5.15621-1.578 T_{3}^{1}=60 \\
i=3, j=0 \\
-1.578 T_{2}^{1}+5.156 T_{3}^{1}-1.578 T_{4}^{1}=60 \\
i=4, j=0 \\
-1.578 T_{3}^{1}+5.156 T_{4}^{1}-1.578 T_{5}^{1}=60 \\
i=5, j=0 \\
-1.578 T_{4}^{1}+5.156 T_{5}^{1}-1.578 T_{6}^{1}=60 \\
i=6, j=0 \\
i=9, j=0 \\
-1.578 T_{5}^{1}+5.156 T_{6}^{1}-1.578 T_{7}^{1}=60 \\
i=7, j=0 \\
-1.578 T_{6}^{1}+5.156 T_{7}^{1}-1.578 T_{8}^{1}=60 \\
i=8, j=0 \\
+5.156 T_{8}^{1}-1.578 T_{9}^{1}=60 \\
i=0
\end{gathered}
$$




$$
\begin{gathered}
-1.578 T_{8}^{1}+5.156 T_{9}^{1}-1.578 T_{10}^{1}=60 \\
i=10, j=0 \\
-1.578 T_{9}^{1}+5.156 T_{10}^{1}-1.578 T_{11}^{1}=60 \\
i=11, j=0 \\
-1.578 T_{10}^{1}+5.156 T_{11}^{1}-1.578 T_{12}^{1}=60 \\
i=12, j=0 \\
-1.578 T_{11}^{1}+5.156 T_{12}^{1}-1.578 T_{13}^{1}=60 \\
i=13, j=0 \\
-1.578 T_{12}^{1}+5.156 T_{13}^{1}-1.578 T_{14}^{1}=60 \\
i=14, j=0 \\
i=15, j=0 \\
-1.578 T_{13}^{1}+5.156 T_{14}^{1}-1.578 T_{15}^{1}=60 \\
i=16, j=0 \\
5.156 T_{16}^{1}-1.578 T_{15}^{1}=107.34 .
\end{gathered}
$$

The above set of simultaneous equations are represented in the matrix from as follows.

$$
A=\left\{\begin{array}{cccccccccccccccc}
5.156 & -1.578 & 0 & 0 & 0 & 0 & 0 & 0 & 0 & 0 & 0 & 0 & 0 & 0 & 0 & 0 \\
-1.578 & 5.156 & -1.578 & 0 & 0 & 0 & 0 & 0 & 0 & 0 & 0 & 0 & 0 & 0 & 0 & 0 \\
0 & -1.578 & 5.156 & -1.578 & 0 & 0 & 0 & 0 & 0 & 0 & 0 & 0 & 0 & 0 & 0 & 0 \\
0 & 0 & -1.578 & 5.156 & -1.578 & 0 & 0 & 0 & 0 & 0 & 0 & 0 & 0 & 0 & 0 & 0 \\
0 & 0 & 0 & -1.578 & 5.156 & -1.578 & 0 & 0 & 0 & 0 & 0 & 0 & 0 & 0 & 0 & 0 \\
0 & 0 & 0 & 0 & -1.578 & 5.156 & -1.578 & 0 & 0 & 0 & 0 & 0 & 0 & 0 & 0 & 0 \\
0 & 0 & 0 & 0 & 0 & -1.578 & 5.156 & -1.578 & 0 & 0 & 0 & 0 & 0 & 0 & 0 & 0 \\
0 & 0 & 0 & 0 & 0 & 0 & -1.578 & 5.156 & -1.578 & 0 & 0 & 0 & 0 & 0 & 0 & 0 \\
0 & 0 & 0 & 0 & 0 & 0 & 0 & 1.578 & 5.156 & -1.578 & 0 & 0 & 0 & 0 & 0 & 0 \\
0 & 0 & 0 & 0 & 0 & 0 & 0 & 0 & -1.578 & 5.156 & -1.578 & 0 & 0 & 0 & 0 & 0 \\
0 & 0 & 0 & 0 & 0 & 0 & 0 & 0 & 0 & -1.578 & 5.156 & -1.578 & 0 & 0 & 0 & 0 \\
0 & 0 & 0 & 0 & 0 & 0 & 0 & 0 & 0 & 0 & -1.578 & 5.156 & -1.578 & 0 & 0 & 0 \\
0 & 0 & 0 & 0 & 0 & 0 & 0 & 0 & 0 & 0 & 0 & -1.578 & 5.156 & -1.578 & 0 & 0 \\
0 & 0 & 0 & 0 & 0 & 0 & 0 & 0 & 0 & 0 & 0 & 0 & -1.578 & 5.156 & -1.578 & 0 \\
0 & 0 & 0 & 0 & 0 & 0 & 0 & 0 & 0 & 0 & 0 & 0 & 0 & -1.578 & 5.156 & -1.578 \\
0 & 0 & 0 & 0 & 0 & 0 & 0 & 0 & 0 & 0 & 0 & 0 & 0 & 0 & -1.578 & 5.156
\end{array}\right\}
$$




$$
B=\left(\begin{array}{c}
375.6 \\
60 \\
60 \\
60 \\
60 \\
60 \\
60 \\
60 \\
60 \\
60 \\
60 \\
60 \\
60 \\
60 \\
60 \\
107.34
\end{array}\right)
$$

Solving the above matrix $A$ and $B$ through LU decomposition method using MATLAB, the value of $T$ matrix can be obtained as follows.

$$
\begin{gathered}
A T=B \\
T=A^{-1} B
\end{gathered}
$$

where $T=$ Unknown temperature matrix.

Incrementing time with one time step $(\Delta t=0.5 \mathrm{~s})$ and continuing the above procedure by substituting temperature of previous time step the temperature for other time steps can be obtained.

Cite this article as: S. Elangovan: Experimental and theoretical investigations on temperature distribution at the joint interface for copper joints using ultrasonic welding. Manufacturing Rev. 2014, 1, 18. 